\title{
CLITEMNESTRA Y LA RETÓRICA DEL ENGAÑO (AG.907-994)
}

\author{
Viviana Gastaldi ${ }^{*}$
}

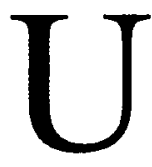

na de las palabras más importantes ( y por cierto ambiguas) de la Orestía y del v siglo ateniense es, sin duda, díke, ya que expresa no sólo la idea de retribución o castigo independiente de un código penal, sino también la justicia racional impartida en las cortes como resultado de un proceso legal organizado. De una u otra forma, tal como lo señala Goldhill " es el término clave para la comprensión del orden social y en ambos casos indica la propia organización de la sociedad como un todo, delineando la recta acción individual y la institución a través de la cual el orden debe ser mantenido"."

En el caso particular de la Orestía, Agamenón es reconocido como el agente de dikê en la destrucción de Troya, ${ }^{2}$ Paris es "el que ha manchado el altar de dikê y Clitemnestra obedece a díke- según sus propias palabras - en la destrucción de Agamenón $^{3}$ ( $A g$. 1432). En la primera pieza de la trilogía, dikê tiene el sentido de retribución o venganza. ${ }^{4}$

Estas consideraciones han llevado a la crítica a manifestar la incoherencia de un pensamiento que postula dikai opuestas y contradictorias, ya que los sujetos

* Universidad Nacional del Sur Bahía Blanca (Argentina)

1 GOLDHILL S. 1992 Reading Greek Tragedy. Cambridge University Press, pág. 31

2 Ag. 813

3 Ag. 1432

4 Electra introduce luego en Coéforas (120) la distinción entre vengadores y jueces. 
GASTALDI, V. Clitemnestra y la retórica...

encargados de penalizar una acción que ha violentado la dikê, lo hacen mediante un castigo que implica una nueva ruptura al orden jurídico. ${ }^{5}$

Es importante la referencia a estos conceptos pues el homicidio de Agamenón da cuenta de una nueva inversión de roles: el agente de Zeus y dikê que castiga a Troya ( y con ello la falta de Paris y Helena), deviene ahora víctima de un nuevo transgresor: Clitemnestra.

Su acción no sólo comporta el homicidio como hecho material y concreto, sino sus palabras y su conducta momentos antes de la consumación del crimen, rasgos que se corresponden con lo que podríamos denominar una "simbólica usurpación del poder". En otras palabras, y haciendo especial hincapié en la conjunción de los elementos esenciales de la representación trágica - esto es discurso y performance, ${ }^{6}$ el regreso de Agamenón y su entrada al oikos conforman la singular antesala del homicidio.

Como señala G. Crane

"This scene dramatizes both visually and verbally the transition from victor to victim, using gesture and action to foreshadow and, in some measure, explain the fate that awaits the returning hero"?

Enmarcada formalmente entre los versos 810-974, la llegada del rey se estructura en una larga resis de saludo - se dirige en primer lugar a la polis, en una primera referencia a Argos y a las divinidades, luego hace alusión a Troya ( caracterizada por la ruina, el dolor y la muerte) y finalmente, se dirige hacia el palacio y hacia el hogar familiar, ( 851 ) no sin antes reflexionar - en una suerte de premonición

5 Tomando como base la objeción socrática ( Eutifrón 8a) en al que se cuestiona la colisión de obligaciones morales opuestas, ya que afirman una contradicción que la razón rechaza, algunos críticos de la tragedia sostienen que el pensamiento de Esquilo, en lo que respecta a la idea de moral y justicia es prreracional y pri mitivo. De este modo, Gagarin afirma con desaprobación que "la coexistencia de dos dikai válidas y opuestas dentro de un proceso general de dike no debe ser identificada con nuestro concepto moral de justicia, ya que resulta algo notablemente incoherente". Citado por M. Nussbaum. 1995 La fragilidad del bien. Fortuna y ética en la tragedia y la filosofía griega, Madrid, pág 54.

6 Con la expresa finalidad de hallar un encuentro entre Taplin y Goldhill que intentan diferentes modos de acercamiento al género trágico, D. Wiles. 1987 "Reading Greek Perfomance", $G \& R$, XXXIV, 2, pág 139, organiza su discusión en torno a una unión de ambos criterios que recupera para el lector moderno una multiplicidad de signos verbales, visuales y gestuales que estructuran el texto y la acción. Observa al rspecto que "Actions, like words, acquire meaning when they are placed within a system of distinctions. Within the ritual of Greek theatre, examples of basic distinctions are comedy and tragedy, entries through skene and parodos, actor and chorus, speech and music, male and females masks".

7 1993, p. 117 
que la audiencia recepcionaría como "ironía trágica": Una imagen de sombra eran realmente quienes parecian serme leales $(839-40)$

La intervención de Clitemnestra (855-913), que interrumpe la transición de su esposo desde el espacio público al privado, se configura en un acto engañoso, tanto verbal como gestual. En el primer aspecto, la manipulación del lenguaje permite crear un discurso que se estructura con una finalidad específica: en una larga resis dirigida al Coro de ancianos y a Agamenón, Clitemnestra se presenta - en apariencia - como modelo de esposa, exhibiendo la imagen conveniente que requería su rol social; de esta forma, intenta convencer a sus dos interlocutores de haber actuado con el comportamiento debido para los intereses del oikos y de la polis. ${ }^{8}$

Enmarcados en lo que podríamos denominar "retórica gestual" los versos 910-911 señalan el comienzo de este ritual de bienvenida que expresa, esencialmente, el deseo aparente de recibir con el honor debido al rey ausente. Al mismo tiempo, indican el inicio de una escena en la que Agamenón quedará simbólica y fatalmente atrapado.

La respuesta de Agamenón (916-917) tal como señala Crane, ${ }^{9}$ marca la primera transgresión de Clitemnestra, ya que el honor, concebido como premio o privilegio que preparaba el retorno del basileus, correspondía que fuera otorgado por otro miembro de la sociedad, obviamente varón y no oikeios. La acción de Clitemnestra viola no sólo su propio espacio en el oikos, sino su posición como mujer.

La alfombra color púrpura que tapiza engañosamente el camino de Agamenón hacia el interior del palacio contiene no pocos simbolismos: en primer lugar, el tejido tenía una función privilegiada en el espacio y el rol femenino; en segundo término, el lugar especial que le confiere Clitemnestra no condice con el aceptado por las normas que regían la vida doméstica; la singularidad del color, en tanto, sumada al tejido es indicativo de una acción dolosa maquinada por una mujer. ${ }^{10}$ Por último, no debemos olvidar la importancia del vestido o de la tela en la economía del oikos. Examinemos detenidamente estas consideraciones.

Si el hombre era, en el mantenimiento del oikos, el encargado de la producción de la fibra (cultivo y recolección), la mujer era el agente de la transformación: la

8 En perfecta relación con los versos 588-614 en los que se observa idéntica manipulación retórica para los mismos fines, es decir, reafirmar una imagen acorde con determinados códigos sociales.

9 CRANE G.1993 "Politics of Consumption and Generosity in the Carpet Scene of the Agamemnon" $C P h, 88$, pág. 120. Sumado a esto, es neecesario recordar que el contexto social en el cual una mujer respetable podía exhibir la riqueza de sus vestidos estaba severamente restringido por su confinamiento espacial; los funerales, al respecto, proveían una rara oportunidad para la mujer casada de ostentar sus atavios fuera de los límites del oikos. Cf. también I. Jenkins.1985 "The ambiguity of Greek Textiles" Arethusa 18, pág. 111.

10 Como señala Buxton, a propósito de la robe que usan Deyanira y Medea "The anti-wife uses 'anti-produce". Citado por Jenkins op. cir, pág. 116. 
GASTALDI, V. Clitemnestra y la retórica...

materia prima, depositada por el varón en el interior del hogar, era objeto de manufactura por la parte femenina. Así resulta claro el sentido de oposición y complementariedad de los roles ( idealizada e internalizada como modelo en la sociedad ):

"Men are providers of items from the outside world and without this provision the family would have difficulty in surviving. Women paly an essential role in transforming these things provided by the men into sources of comfort and nourishment"11

Importante de destacar en este punto es el hecho de que en la sociedad homérica y pos- homérica, la riqueza y los vestidos no sólo eran símbolo de autoridad y poder (dentro y fuera del oikos) sino que constituían elementos básicos de las relaciones interpersonales. La tela o el vestido era un objeto de vital significación en el acuerdo matrimonial (los artículos de tejido formaban parte de una dote (proix) que la mujer ingresaba en su nuevo oikos), y también un elemento de interacción sexual, un don económico de intercambio acorde con las convenciones de la xenia. Ligada al tejido, la mujer, con las restricciones ya mencionadas, (cf. nota 6) se convierte en protectora de la producción intra-doméstica.

Ahora bien: en el texto esquíleo, la idea de tejido, de tela, aparece bajo diferentes nombres, según aparece en los versos 921, 923, 926, 946, 949. No está clara en el texto la distinción entre vestido o alfombra, pero sí es seguro de que - y en esto coincidimos con Scott Morrell - se trata de la idea general de un tejido. ${ }^{12}$

Cabria aquí considerar el hecho de que la alfombra no era una parte regular de la cultura griega y que el término tápes parece haber sido una importación foránea adoptada por los griegos sólo tardíamente. ${ }^{13}$ Estas reflexiones nos conducen al siguiente punto: el lugar que le otorga Clitemnestra. Si en verdad el objeto que ella coloca sobre el piso era un largo y espléndido manto, un objeto de producción femenina, desde el punto de vista de la tensión dramática y de la receptividad de la audiencia, tal objeto no podía ser sacado fuera del oikos y puesto en el suelo: la persuasión que Clitemnestra ejerce para que Agamenón camine sobre él, no hace otra cosa que intensificar y hacerlo partícipe de esta perversión.

Tan importante como la idea de tejido es el concepto de púrpura: si el tejido era una actividad que el oikos se procuraba por sí mismo, el arte de teñir la tela era

11 JENKINS 1985, p. 110

12 MORRELL, K. Scott. 1997. "The fabric of persuasion" $C J,(92,2)$, pp.141-65 El término hufás es el nombre con que Orestes en Coéforas señala el manto en el que su madre envolvió al rey para darle muerte y es también el objeto-prenda de reconocimiento - que lo une a Electra.

13 CRANE G. 1993, p. 122 
una ocupación que requería de elementos extraños al hogar: en el tejido color púrpura que Clitemnestra despliega ante su esposo, están simbolizados los dos aspectos de la economía familiar: la producción y el comercio, tal como lo refieren las palabras de Agamenón poco antes de iniciar el trayecto (945-50).

La ostentación y la destrucción de la riqueza del palacio, propiciada por Clitemnestra y ejecutada por Agamenón, representa en el texto no sólo la imposición de la autoridad femenina, que determina las condiciones de la re-integración social de Agamenón, sino la oposición al ethos normal del oikos, cuya finalidad esencial era la continuidad y la estabilidad de su riqueza y sus posesiones. ${ }^{14}$

La resis siguiente de Clitemnestra (959-974) pronunciada mientras Agamenón está entrando en el palacio, contiene algunos elementos significativos. En primer lugar, ratifica el poder económico del oikos, basado en los dos aspectos que señaláramos anteriormente. Es importante mencionar en este punto, y en relación con el simbolismo del color púrpura, la interconexión entre éste , la sangre y luego, la muerte. ${ }^{15}$ Otro rasgo relevante en la estructuración del discurso, lo constituye la extensa metáfora con que Clitemnestra se refiere a la fertilidad del oikos, asociada a la imagen del varón como elemento vital de consumación (966-972)

La referencia a Agamenón (como andros teleios) anticipa sin duda el momento del término de su vida, pero al mismo tiempo y paradójicamente, expresa la importancia del "señor" en el oikos.

Por último, la invocación a Zeus en este contexto resulta reveladora: telos aparece tambien en conjunción con gamos: gamos es en sí mismo un telos. Zeus teleios tiene una doble significación: en la esfera política, el sentido de la soberanía, en su aspecto social el poder de gobernar el matrimonio. La enfática repetición de telos, término también asociado a la metáfora del tejido $(908,934)$ sugiere la conjunción de tres elementos: la pisada de la alfombra, la imprecación de Clitemnestra y la muerte de Agamenón.

Todos ellos confluyen a su vez, en un único significado: la transgresión de los códigos del oikos. Si Zeus téleios, en su aspecto de Soter, era el dios responsable de la preservación y la perpetuidad de la línea familiar, también estaba asociado con la muerte: beber a la salud de Zeus teleios era hacerlo por un hombre muerto. Explotando

14 GOLDHILL, S. op. cit, pág.11.

15 Cf. al respecto L. MccLure 1997. "Clytemnestra's binding spell. (Ag. 958-974) , CJ, (92,2), pág 133, nota 40 en la que se cita dicha relación tomando como fuente la épica homérica (ll. 5.82-83; 16.334; 20.447.)

16 L. Mcclure. op. cit, pp.123-140, esteblece un paralelo entre el énfasis de ciertos rasgos estilísticos (aliteración, repeticiones, asonancia, frases rítimicas y metáforas) y las fórmulas encantatorias cuyos ejemplos atestigua la tradición literaria griega. En este sentido, es posible comprender la intervención de Clitemnestra como un hábil ejercicio de peithó, considerada en su aspecto negativo. Para este tema, ver M. Detienne. 1986 Los maestros de verdad en la Grecia Arcaica, Madrid, pp. 59-85. 
GASTALDI, V. Clitemnestra y la retórica...

pues esta ambigüedad, Clitemnestra lo invoca en tanto guardian del oikos, pero simultáneamente, sus palabras constituyen un acto performativo de venganza. ${ }^{16}$

El Coro, en tanto, vaticina con una metáfora ${ }^{17}$ una nueva violación al ethos del oikos: el homicidio del rey. La acción que compromete no sólo a Clitemnestra sino a Agamenón mismo es presentida por los ancianos como portadora de una nueva desdicha ( 1009-1012).

Si y tal como decíamos anteriormente, el nostos de Agamenón configura una escena en la que el lenguaje (la manipulación retórica), el gesto y la imagen conforman una verdadera dinámica de competición y control del oikos, debemos precisar el sentido de la asociación entre la palabra femenina, el tejido y la magia.

Si es verdad que la operatividad y la fuerza de la palabra, usada como un habitual recurso femenino para "vencer" dialécticamente al hombre está atestiguada ampliamente en la tradición literaria griega ${ }^{18}$, no es menos cierto el hecho de que tejido y magia se relacionan marcando un rasgo femenino de poder. Tal como observa A.Bergren" "the tricky ambivalence ascribed to the speech of women is consonant with the semiotic character of weaving and of graphic art in general". Es particularmente en la tragedia ${ }^{20}$ en donde el vestido aparece como un objeto engañoso de seducción y destrucción: el término poikílos $(A g .923,933,936)$ asocia la tela con la magia, pues designa, paradójicamente, una forma concreta de encantamiento amoroso que ocasiona la muerte.

El tejido, actividad femenina por excelencia, y el lenguaje ambivalente, constituyen los rasgos que definen, de manera inequivoca, el modo con que una mujer invierte las jerarquías de dominación en el espacio privado.

En suma, la conjunción de estos elementos en el ámbito escénico conforma el rasgo principal de un regreso que constituye en realidad, el preludio de un homicidio: el orden y la prosperidad del oikos devienen su exacto reverso.

17 Y sin embargo, mi corazón, sin ayuda de lira, canta por dentro el fúnebre canto de Erinis, sin que nadie se lo haya enseñado, sin tener ya valor para abrigar alguna esperanza" (990-994).

18 Calipso, Circe y Penélope en Odisea, Helena en la épica homérica y en Eurípides, Deyanira en Traquinias, Medea y Fedra en Eurípides constituyen claros ejemplos de persuasión dolosa. Ver al respecto las categorias de peitho que establece R. Buxton .1982 Persuasion in Greek Tragedy, Cambridge, pp. 58-66.

19 BERGREN, A.1983 "Language and the female in early greek thought" Arethusa, 16, p. 71.

20 Traquinias de Sófocles y Medea de Eurípides son piezas en las que los tejidos, asociados con el poder femenino "function as instruments of retribution and seduction" MACCLURE, L. op.cit, p. 127. 